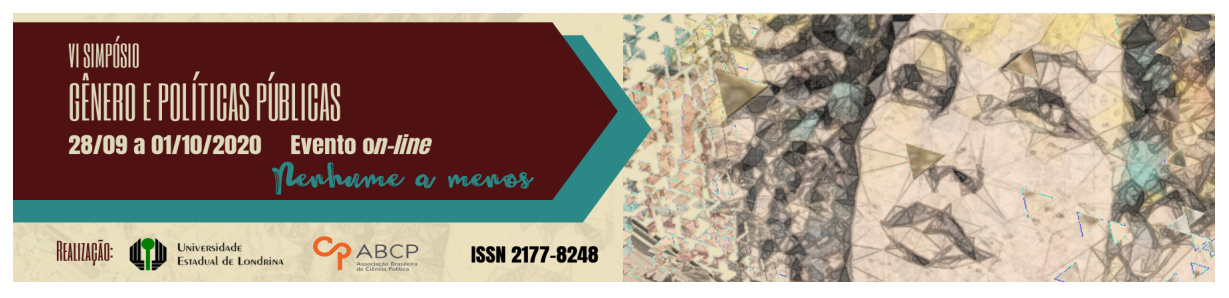

\title{
Refugiadas: protagonismo, condições de vida no Brasil e o trabalho como mecanismo de integração
}

\author{
Ana Paula Bagaiolo Moraes ${ }^{1}$; Maíra Furquim Lunardello ${ }^{2}$
}

\begin{abstract}
Resumo
$\mathrm{O}$ artigo se propõe a analisar o protagonismo das refugiadas no âmbito das migrações e como condições de trabalho dignas viabilizam a integração destas mulheres no Brasil. Como metodologia, a pesquisa tem caráter qualitativo, por meio da revisão bibliográfica de pesquisas e artigos científicos, livros e legislações. O referencial teórico parte da investigação acerca da relação entre gênero e refúgio, bem como da análise sobre políticas públicas de acolhimento, condições de vida no Brasil, acesso ao trabalho digno e integração local. Quanto aos possíveis resultados, a pesquisa apresenta as refugiadas como agentes ativos das migrações, evidenciando a realidade destas mulheres no país e como o trabalho é um efetivo meio de integração local.
\end{abstract}

Palavras-chave: mulheres refugiadas; trabalho; Brasil.

\section{Female refugees: protagonism, living conditions in Brazil and work as an integration mechanism}

\begin{abstract}
The article proposes to analyze the protagonism of the female refugees on the context of migration and how decent work conditions facilitates the integration of these women in Brazil. As methodology, the research has a qualitative method, through bibliographic review of scientific researches and articles, books and legislations. The theoretical frame starts from the investigation of
\end{abstract}

\footnotetext{
1 Advogada, professora universitária, doutora em direito político e econômico pela Universidade Presbiteriana Mackenzie. E-mail: apbagaiolomoraes@gmail.com

2 Advogada, graduada em direito pela Faculdade de Direito de Franca. E-mail: mairafulu@gmail.com
}

GT 12 - Gênero, refúgio e migrações 
the relationship between gender and refugee, as well as the analysis of public reception policies, living conditions in Brazil, access to decent work and local integration. As for the possible results, the research presents the female refugees as active agents of migration, highlighting the reality of these women in Brazil and how work is an effective means of local integration.

Keywords: female refugee; work; Brazil.

Ante a atual notabilidade que se dá ao fenômeno migratório, percebe-se relevante tratar desta temática sob a perspectiva de gênero, revelando que as mulheres consistem em agentes ativos deste fenômeno, cujo protagonismo não foi estampado na história das migrações, e que a integração social deste grupo pode ser alcançada por meio da inserção laboral nos países de destino, como o Brasil.

Migrar, então, consiste na mobilidade de indivíduos, no âmbito nacional ou internacional, motivada por diversas causas e composta por diferentes atores.

No tocante às causas que ensejam a migração contemporânea, a Organização das Nações Unidas (ONU) citada por João Brígido Bezerra Lima aponta que:

As migrações apresentam causas diversas, como tortura, grave e generalizada violação de direitos humanos, opressão política, transformações econômicas, aperfeiçoamento educacional e reunião familiar, que sinalizam aos países, sejam de origem, trânsito e destino, que os encaminhamentos são convergentes e que potencializam a cooperação internacional (2017, p. 24).

Compreende-se, assim, que o fenômeno das migrações internacionais "envolve questões de direitos humanos, globalização dos mercados de trabalho, desenvolvimento econômico, fluxo de recursos, migração irregular e formação de grupos vulneráveis, onde se incluem os refugiados" (SOLOMON; BORTSCH apud LIMA, 2017, p. 24). 
Deste modo, além do contemporâneo processo de globalização, a discrepância de renda entre os países, os contextos socioeconômicos frágeis de alguns territórios, os conflitos armados, as condições indignas de trabalho e os desastres naturais configuram fatores que motivam indivíduos a migrarem em busca de locais que lhes proporcionem melhores condições de vida.

Estas movimentações de indivíduos provocam transformações econômicas, sociais, culturais e políticas tantos nos territórios de origem quanto nos territórios de destino, propiciando o surgimento de novas identidades e possibilitando que os migrantes reconstruam, negociem ou reafirmem tradições, credos e relações de poder (HALL, 2003, p. 6667).

Desta forma, o processo migratório é capaz de alterar ou ajustar imposições de gênero, possibilitando que homens e mulheres recondicionem a sua identidade.

Relativamente à natureza das migrações, os indivíduos podem se deslocar de maneira espontânea ou de forma forçada, quando a movimentação decorre de fatores que oferecem riscos à vida destas pessoas, como, por exemplo, desastres naturais, escassez de recursos financeiros, conflitos armados, discriminação e violências de gênero, categoria na qual encontram-se os refugiados.

Neste contexto, encontram-se as mulheres migrantes. Contudo, observando o processo migratório sob a perspectiva de gênero, constata-se que as razões que ensejam a mobilidade destas mulheres alcançam outras dimensões, pois, assim como em todas as outras esferas sociais, o migrante homem é apresentado com o protagonista, por motivos políticos e econômico deste fenômeno, ignorando-se a presença da mulher neste cenário e apresentando-a como um ser que migra por dependência a alguma figura masculina.

Partindo, então, da concepção formulada por Simone de Beauvoir, gênero é uma construção social e cultural, intencionalmente criado, o qual impõe às pessoas determinadas condutas categorizadas 
de acordo com a relação homem-mulher. Ou seja, ao nascer, o indivíduo deverá comportar-se segundo às normas impostas ao seu gênero (masculino - feminino) (BEAUVOIR, 1970, p. 9).

Além disso, Beauvoir explica que a palavra "homem" não é um termo genérico e despretensioso para representar a humanidade, mas sim a retratação da desigualdade de gênero, que apresenta o homem como ser superior e a mulher como um indivíduo insignificante (BEAUVOIR, 1970, p. 9), sendo justamente este imperativo que ocasiona a mobilidade de inúmeras mulheres, além de torná-las invisíveis no cenário das migrações.

Isto posto, percebe-se que o processo de decisão atrelado à migração pode se relacionar com questões de gênero, pois a mobilidade humana sofre influência das interações sociais e familiares criadas e estruturadas para a manutenção de uma sociedade patriarcal, fazendo com que as mulheres sejam consideradas como seres passivos do processo migratório e não como atores sociais (MORALES, 2015, p. 24).

Nesta perspectiva, destaca-se a compreensão de Heleith Saffioti sobre a concepção de uma sociedade patriarcal:

Em todas as outras esferas, quer de trabalho, quer de vida ociosa, a mulher sempre foi considerada menor e incapaz, necessitando da tutela de um homem, marido ou não. A felicidade pessoal da mulher, tal como era então entendida, incluía necessariamente o casamento. Através dele é que se consolidava sua posição social e se garantia sua estabilidade ou prosperidade econômica. Isto equivale a dizer que, afora as que permaneciam solteiras e as que se dedicavam às atividades comerciais, as mulheres, dada sua incapacidade civil, levavam uma existência dependente de seus maridos. E a asserção é válida quer se tomem as camadas ociosas em que a mulher dependia economicamente do homem, quer se atente para as camadas laboriosas nas quais a obediência da mulher ao marido era uma norma ditada pela tradição. Sob a capa de uma proteção que o homem deveria oferecer à mulher em virtude da fragilidade 
desta, aquele obtinha dela, ao mesmo tempo, a colaboração no trabalho e o comportamento submisso que as sociedades de família patriarcal sempre entenderam ser dever da mulher desenvolver em relação ao chefe da família (SAFFIOTI, 1976, p. 33)

A partir da leitura de Saffioti, compreende-se, então, que as imposições patriarcais criam a imagem da mulher como submissa e dependente ao homem, gerando reflexos em diversos cenários sociais, inclusive, no migratório.

Contudo, atualmente, conforme a Organização Internacional para Migrações (OIM), alterou-se a composição de gênero dos migrantes internacionais, ocorrendo a "feminização" da migração (2018, p.185). As mulheres, então, passam a constituir em 2019, aproximadamente, metade da população migrante internacional no mundo (OIM, 2020, p. 22).

Estes deslocamentos femininos são ocasionados por diversos fatores, sendo que, em inúmeros casos, estão condicionados à busca por um local onde a sobrevivência destas mulheres seja garantida.

Assim, mulheres migram motivadas pela reunificação familiar, pela busca por trabalho, pela obtenção de refúgio ou asilo, pela procura por melhores condições econômicas e laborais, pela conquista de maior independência familiar e pela fuga da violência doméstica (MORALES, 2015, p. 25), dos casamentos forçados e das discriminações de gênero, de raça, de classe e de sexualidade.

Nesse seguimento, elucidam Milesi e Marinucci:

Ao tornar-se a principal provedora econômica da família, a mulher migrante pode quebrar determinadas tipificações de gênero que, em muitos lugares, encaixotam o universo feminino no ambiente reprodutivo, numa condição de subordinação em relação ao homem. A migração, a princípio, contribui na luta contra a pobreza e, ao 
mesmo tempo, para a modificação de formas de descriminação da mulher (MILESI; MARINUCCI, 2015, p. 62).

Porém, também, afirmam os referidos autores:

A migração, portanto, pode ser sinal ou instrumento de empoderamento por parte da mulher. Mas nem sempre isso é verdadeiro. Com frequência, as mulheres, embora migrem sozinhas, carregam um projeto migratório familiar: elas devem sustentar os familiares com suas remessas. A incorporação no espaço produtivo, portanto, não elimina a responsabilidade em relação àquele reprodutivo. Essa responsabilidade as coloca em uma situação de maior vulnerabilidade e, não raramente, as obriga a aceitar duras condições de trabalho e tolerar violações hediondas dos próprios direitos, para garantir as remessas. Em resumo, não há dúvida de que mudou o perfil da mulher migrante, embora essa mudança nem sempre represente uma melhoria em termos de autonomia e respeito dos direitos fundamentais (MILISE; MARINUCCI, 2015, p. 58).

Ou seja, em consonância com Milesi e Marinucci, compreendese que, embora a migração possibilite o enfretamento às imposições de gênero, quando há a inter-relação entre gênero e trabalho, percebe-se estas ainda se perpetuam, pois, assim como as autóctones dos países receptores ocupam posições de trabalho inferiores e são menos remuneradas que os homens, as mulheres migrantes também são afetadas por esta discrepância, todavia de forma mais aguda.

Quanto a isto, retomando a concepção de Saffioti sobre uma sociedade patriarcal, nota-se que a opressão de gênero que destina a mulher ao exercício do trabalho doméstico, estende-se no âmbito laboral. Assim, as migrantes são submetidas, nos países receptores, a trabalhos que se assemelham às funções domésticas, como de faxineira, 
cozinheira, costureira e doméstica, mesmo tendo formação superior ou experiência em diversas áreas.

Inclusive, sobre a condição laboral exposta, Morokvasic denuncia a existência do discurso de que os trabalhos informais, mal remunerados e precários ocupados por mulheres migrantes são considerados como bênçãos por libertá-las das opressões que as vitimizavam em seus países de origem (MOROKVASIC, 2012, p. 889). No entanto, este discurso apresenta-se problemático, pois a vulnerabilidade vivenciada anteriormente não justifica qualquer violação aos direitos humanos destas mulheres nos países de destino.

Diante disso, apontam Milesi e Marinucci:

[...] a exploração de milhões de mulheres migrantes e refugiadas oriundas de países do Sul do mundo em trabalhos domésticos e de cuidado ou na indústria têxtil e no agronegócio, em nossa opinião, representa uma severa denúncia contra o modelo vigente de desenvolvimento de muitos países, que reproduzem relações neocoloniais e discriminatórias, sem promover o respeito dos direitos humanos e da igualdade de gênero (MILESI; MARINUCCI, 2015, p. $65)$.

Sendo assim, infere-se que, embora não sejam retratadas desta forma, as mulheres são protagonistas do fenômeno migratório, deslocando-se por razões políticas e socioeconômicas. Entretanto, apesar da mobilidade feminina simbolizar "empoderamento", como exposto por Milesi e Marinucci, ainda é afetada por imposições de gênero que, além de ser um fator motivador do deslocamento de mulheres, colocam-nas como seres invisíveis do cenário migratório e, ainda, faz com que a vulnerabilidade a qual estavam expostas nos países de origem se perpetuem nos países de destino.

No tocante especificamente às mulheres refugiadas, que, em 2018 , consistiam entre $47 \%$ a $49 \%$ do número de pessoas refugiadas no mundo (UNHCR, 2020, p. 39), estas deslocam-se para salvar sua vida e sua liberdade. Tal deslocamento consiste, assim, em uma luta por 
sobrevivência, que inicia quando a refugiada abandona, forçosamente, seu país de origem, se expande pelo trajeto até o país de destino e não termina com a chegada no novo território.

Ao chegarem nos países de destino, as mulheres refugiadas ainda enfrentam dificuldades para obter emprego e moradia, aprender novos idiomas, lidar com as diferenças culturais, além de serem vítimas de preconceitos e xenofobia.

Estas mulheres consistem em um dos grupos mais vulneráveis no âmbito das migrações, devido à ausência de políticas públicas de acolhimento específicas para suas demandas, aos abusos, principalmente sexuais, à discriminação quanto à condição de mulher e refugiada e às violências de gênero que as afetam em diversas proporções.

Ante o exposto, infere-se que milhares de mulheres se deslocam forçosamente em busca de um local onde possam viver de forma digna. Este cenário é descrito por Milesi e Marinucci:

Migram as mulheres no mundo contemporâneo: vendidas como escravas ou fugindo de desastres naturais ou de violência; em busca de renda para o sustento de seus familiares ou à procura de maior autonomia. Migram as mulheres em travessias em que os sonhos e os pesadelos se entrelaçam, em que a vontade de sair se coaduna com o desejo do retorno. A migração, assim, se torna, não raramente, uma experiência de fragmentação, onde nem sempre o coração acompanha os caminhos dos pés (MILESI; MARINUCCI, 2015, p. 55).

As refugiadas são, desta maneira, os indivíduos mais vulnerabilizados no fenômeno da mobilidade humana, em decorrência do não avanço ao combate à desigualdade de gênero, que se expressa na precarização do trabalho feminino, nas distintas formas de violência citadas acima e no não reconhecimento dos seus protagonismos.

Desta feita, faz-se imprescindível reconhecer as mulheres migrantes e refugiadas como protagonistas das migrações, além tornar 
efetivo os empenhos na luta contra à desigualdade de gênero que consiste em um fator determinante na mobilidade forçada de milhares de mulheres e, também, potencializa as violências sofridas, sobretudo, pelas refugiadas.

Direcionando a análise para o Brasil como um país receptor de mulheres em condições de refúgio, a fim de que estas se adaptem às mudanças culturais, linguísticas e socioeconômicas para constituírem parte integrante deste território, faz-se necessário que sejam estabelecidos mecanismos capazes de propiciar a redução da situação de vulnerabilidade a qual estavam expostas.

Tais mecanismos consistem em políticas migratórias que se referem, não só quanto sobre quem tem permissão ou não para possuir o status de refugiada, bem como quanto ao acesso a políticas públicas das quais dispõem os autóctones, além daquelas planejadas especificamente para atender as suas necessidades.

No caso do Brasil, destaca Carmem Lussi:

O Brasil está em seus primeiros passos nas respostas às demandas específicas da população migrante, está aprendendo com os novos fluxos que já não se assimilam anonimamente aos tecidos sociais como por vezes aconteceu com fluxos menores, no passado recente. É uma aprendizagem que leva a reinventar a relação da população autóctone e de seu governo com pessoas, famílias e grupos de imigrantes para além do que foi a migração histórica, que hoje é sentida como uma experiência distante cultural e socialmente. Essa reinvenção marca a abordagem com que os temas relativos à mobilidade humana são tratados e a capacidade de pensar, planejar e implementar serviços que representam e fomentam o acesso a direitos e processos progressivos de cidadania para toda a população, sem exclusão de quem nasceu em outro país (LUSSI, 2015, p. 137). 
Contudo, evidencia-se que o fenômeno migratório expõe desigualdades e incoerências relativas ao acesso às políticas públicas. Neste sentido, aponta Lussi que:

Não existe a igualdade em contextos de pluralidade sociocultural, menos ainda em contextos onde sujeitos migrantes interagem com autóctones, por vezes convergem e sempre se cruzam na luta por políticas públicas adequadas e, possivelmente, formuladas para garantirem equidade de tratamento e de acesso a direitos, bens e serviços. Homens e mulheres migrantes, em sua condição de estrangeiros, representam uma diferença imprescindível nos contextos locais onde buscam inserir-se, normalmente, como concidadãos "iguais" a todos os demais habitantes de um determinado território (2015, p. 136).

Desta forma, pode-se inferir que as desigualdades citadas se relacionam com a situação de vulnerabilidade que sujeita estas mulheres à exclusão. Logo, ao invisibilizar as diversidades das refugiadas, as políticas públicas já existentes geram um efeito contrário: ao invés de promover a integração social no país, fortalecem o estado de vulnerabilidade.

Sendo assim, entende-se que políticas públicas desenvolvidas para atender às demandas peculiares destas mulheres promovem a integração na sociedade brasileira, previnem que seus direitos sejam violados e possibilitam que as violências sofridas anteriormente à condição de refúgio não sejam potencializadas no Brasil ou que tampouco sejam vítimas de novas violências.

Deste modo, inserir as refugiadas em programas e políticas já existentes no Brasil pode limitar suas possibilidades de decisão e de "empoderamento", já que não manifestarão discursivamente no processo de elaboração dos mecanismos pensados para proporcionarlhes novas oportunidades de vida (MOREIRA, 2014, p.91). 
Para retratar este sistema de integração, é imprescindível analisar o arcabouço institucional nacional, incluindo seus agentes estatais e não estatais, bem como a condição de vida das refugiadas no país.

A temática do refúgio no Brasil somente foi institucionalizada com a aprovação da Lei n. ${ }^{\circ} 9.474$ de 1997, a qual estabeleceu a definição do termo refugiado, abordando aquela estabelecida na Convenção Relativa ao Estatuto dos Refugiados de 1951 e, também, o conceito ampliado promovido pela Declaração de Cartagena de 1984

A supracitada legislação promoveu, ainda, a criação do CONARE. Tal órgão se consolida como uma estrutura tripartite, pois engloba instituições não estatais envolvidas com o tema do refúgio no país, organização internacional e o governo nacional.

A Lei n. ${ }^{\circ} 9.474$ de 1997 é, então, considerada pelos organismos internacionais como inovadora, todavia em seus dispositivos somente trata-se de assuntos referentes à documentação.

Além desta legislação, em 2017, foi promulgada a Lei no 13.445 , denominada "Nova Lei de Migração", em decorrência da intensificação migratória contemporânea para o Brasil e a necessidade de colocar em pauta políticas de acolhimento para os imigrantes e refugiados.

A "Nova Lei de Migração" apresenta-se como uma inciativa avançada, elaborada ante uma perspectiva humanitária capaz de amparar, de diversas formas, as mulheres refugiadas. Como exemplo de inovações benéficas, esta legislação prevê o direito de reunião para fins pacíficos, de associação sindical, de amplo acesso à justiça e a à assistência jurídica integral gratuita, de exigência de cumprimento de obrigações legais e contratuais trabalhistas e de aplicação de normas de proteção ao trabalhador, além de prever uma série de princípios e diretrizes reguladores nas novas políticas migratórias, a fim de coibir o racismo e a xenofobia. 
Contudo, importante ressaltar que a Lei $\mathrm{n}^{\mathrm{o}}$ 13.445/2017 sofreu alguns vetos presidenciais antes de ser sancionada, sendo que tais vetos representam que os migrantes ainda são vistos como um problema de segurança nacional (VENTURA, 2018) e, de acordo com Assis:

convive com as contradições e paradoxos de um país que tem um discurso de acolhimento aos imigrantes, mas ao mesmo tempo, continua tratando certos grupos de migrantes na categoria de indesejados e cria mecanismos que podem favorecer a migração qualificada produzindo seletividade migratória (2018, p. 621).

Embora a Lei $\mathrm{n}^{\circ}$ 9.474/1997 e a Lei $\mathrm{n}^{\circ} 13.445 / 2017$ sejam vistas como inovadoras quanto ao contexto migratório, nestas não foram detalhados os parâmetros para a concretização da integração local da população de refugiadas nos aspectos sociais, econômicos, políticos e culturais, por exemplo, além de não estabelecer os meios de acesso às políticas públicas já existentes.

Outrossim, entende-se necessário tratar as refugiadas como agentes ativos do processo migratório, a fim de que não sejam inseridas em projetos predeterminados de políticas públicas que não englobam suas particularidades. Quanto a isto, destaca-se que:

No campo das migrações, é importante que a política migratória e as políticas públicas levem em conta as especificidades de homens e mulheres migrantes, observando que determinada ação governamental pode ter reflexos distintos sobre mulheres e homens. $\mathrm{Ou}$ seja, necessária a preocupação com a transversalidade das políticas públicas para que contemplem o viés de gênero em sua formulação, ao mesmo tempo em que observem a interseccionalidade das discriminações sobre as mulheres. Por outro lado, cabe a discussão sobre a aplicação de um direito antidiscriminatório, buscando soluções adequadas para a promoção da igualdade de combate a discriminação (COSTA; SCHWINN, 2018, p. 205). 
Diante desta conjuntura, remetendo à estrutura tripartite citada acima, a sociedade civil, preponderantemente, tem gerado iniciativas para promover a integração destas refugiadas no Brasil, apesar de existir a participação do ACNUR e do Estado (MOREIRA, 2014, p. 93).

Embora exista este sistema tripartite, resiste, ainda, uma ausência de recursos econômicos e de políticas públicas de integração das refugiadas na sociedade, pois o governo brasileiro, em relação ao acesso destas mulheres às políticas já existentes ou na implementação de políticas voltadas exclusivamente para suas necessidades, permanece alheio ou omisso, transferindo à sociedade civil, por meio de instituições religiosas e suas redes de apoio, a responsabilidade de efetivar aquilo que seria sua função.

Interessa, deste modo, analisar as características socioeconômicas das refugiadas no país. Os estudos que embasam esta análise apontam que as refugiadas e refugiados, em 2007, estavam inseridas em âmbitos familiares pertencentes às classes mais baixas (AYDOS; BAENINGER; DOMINGUES, 2007, p.10), avaliaram as condições de trabalho como insatisfatórias, relataram dificuldades de acesso a serviços públicos de saúde moradia e de validação dos seus diplomas universitários e, ainda, declararam sofrer discriminações pelos autóctones, afetando, assim, a integração local (MOREIRA, 2014, p. 86).

Outro fato relevante, refere-se ao fato de que, 35,7\% de refugiados e refugiadas alegaram não saber avaliar o CONARE ou não o conheciam, sendo que, como já destacado, este órgão foi criado justamente para cuidar da população de refugiados residentes no Brasil (MOREIRA, 2014, p. 86).

Além disso, por meio destes referenciais teóricos, observa-se que refugiados e refugiadas estão sujeitos a violações aos seus direitos humanos no Brasil, bem como desconhecem iniciativas voltadas à garantia de sua proteção (BRASIL, 2015, p. 158). Estes indivíduos também enfrentam dificuldades para se adaptarem ao idioma, sendo 
este um obstáculo para acesso a serviços públicos e para obtenção de trabalho, e tais dificuldades possuem maior gravidade comparadas com as enfrentadas pela população autóctone (BRASIL, 2015, p. 159).

Estes estudos também possibilitaram verificar que os grupos mais vulneráveis no Brasil são compostos por refugiadas, crianças e idosos (BRASIL, 2015, p. 136).

Partindo-se para uma investigação atualizada sobre a situação de vida das refugiadas no Brasil, o "Perfil Socioeconômico dos Refugiados no Brasil" elaborado com as informações obtidas entre os anos de 2018 e 2019, apura que um grande número de refugiados e refugiadas não conseguiram revalidar seus diplomas, residem em domicílios coletivos, alugados ou cedidos e em regiões precarizadas, apresentam renda incapaz de cobrir suas despesas (ACNUR, 2019, p. 56), revelam índice de desemprego mais elevado do que a média nacional (ACNUR, 2019, p. 8), desconhecem seus direitos e os serviços de assistência social são pouco utilizados (ACNUR, 2019, p. 12), expressam o interesse de votar em pleitos políticos e relatam discriminação quanto à raça, à etnia, à sexualidade cometidas por cidadãos brasileiros, autoridades policiais e servidores públicos (ACNUR, 2019, p. 14-5).

Salienta-se que, embora as mulheres refugiadas enfrentem problemas devido à ausência de políticas públicas efetivas no Brasil tanto quanto os outros grupos, reitera-se que estas revelam-se singulares nesse processo de integração local, pois agrega-se aos obstáculos socioeconômicos, as imposições de gênero.

Sendo assim, malgrado o Brasil possua uma inovadora legislação sobre refugiados, percebe-se o quanto são falhos os mecanismos voltados a assegurar o acolhimento e a integração local destas mulheres, já que há dificuldades de acesso, principalmente, a serviços públicos e trabalhos dignos, além das discriminações sofridas devido ao gênero e à condição de refúgio.

Neste seguimento, aponta Moreira: 
Ao analisarmos esse processo no Brasil, há dificuldades em diversas esferas da integração, tanto em termos "funcionais" quanto políticos e de interação social e cultural. Problemas se colocam no tocante ao acesso a serviços públicos (como saúde e educação) e programas sociais, condições de trabalho, além do sentimento de discriminação identificado por refugiados que vivem no país. Somam-se a eles a ausência de integração plena na esfera política. Maiores esforços merecem ser envidados, portanto, para tornar tal estrutura institucional mais efetiva, fortalecer o apoio proporcionado pelos atores envolvidos e, acima de tudo, aprimorar as condições de vida aos refugiados aqui acolhidos (MOREIRA, 2014, p. 96).

Especificamente em relação ao acesso ao trabalho, o ordenamento jurídico brasileiro, mediante a Constituição Federal de 1988, a Lei $\mathrm{n}^{\circ} 13.474 / 2017$ e a Lei nº 13.445/2017, garante às refugiadas o acesso ao trabalho e às proteções trabalhistas das quais dispõe os autóctones.

Entretanto, estas mulheres, em decorrência da condição de refúgio e das desigualdades de gênero, representam um dos grupos da classe trabalhadora com maior grau de vulnerabilidade e, por esta razão, são atingidas, substancialmente, pelas previsões na legislação trabalhista que buscam atender às exigências mercadológicas em detrimento dos direitos dos trabalhadores.

Neste sentido, dispõe Marinucci:

É nesse clima geral que milhões de migrantes e refugiados se inserem no mercado de trabalho dos países de trânsito e de destino. Apesar das legislações de muitos desses países reconhecerem, no papel, a igualdade de direitos laborais entre estrangeiros e nacionais, registra-se com frequência uma maior vulnerabilidade dos primeiros, vulnerabilidade que se acentua quando a condição migratória se intersecciona com questões de gênero, etnia ou religião. Assim sendo, guardadas as devidas 
exceções, os trabalhadores migrantes são os mais atingidos pelos efeitos da atual conjuntura, sobretudo em termos de desemprego, subemprego e sobrequalificação (MARINUCCI, 2017, p. 01).

Tais desigualdades de gênero são refletidas nos lugares ocupados pelas refugiadas no mercado de trabalho brasileiro. Geralmente, apesar de possuírem ensino superior e experiência em diversas áreas, quando obtêm acesso a trabalho, são condicionadas a laborarem como costureiras, faxineiras, cozinheiras e domésticas, por exemplo, sendo estes serviços mal remunerados e símbolos da sociedade patriarcal brasileira.

Ademais, estas mulheres estão sujeitas à terceirização, a trabalhos por demanda e temporários, fazendo com que sobrevivam em meio à instabilidade, às horas extenuantes, às demandas repetitivas e às baixas remunerações.

Constata-se, também, que a dificuldade com o idioma e o desconhecimento sobre os seus direitos, faz com que as refugiadas sejam suscetíveis a firmarem contratos de trabalhos que violem seus direitos ou deixem de buscar proteção jurídica por desconhecimento sobre a legislação trabalhista.

Neste seguimento, exibe-se os dados do Perfil socioeconômico dos refugiados no Brasil:

O "mercado de trabalho" foi apontado como o principal obstáculo em conseguir emprego por 227 entrevistados $(46,1 \%)$. Contudo, há outros obstáculos que se somam, tais como a falta de domínio do idioma (citado 148 vezes) e ser estrangeiro (citado 99 vezes), foram lembrados por mais de $20 \%$ dos entrevistados. Em seguida, temos a falta de recursos para buscar trabalho (citado 93 vezes), falta de documentos (citada 54 vezes) e o preconceito racial (citado 53 vezes). Deficiência na formação escolar (citado 35 vezes) e 'não ter com quem deixar os filhos' (citado 18 vezes) completam a lista (ACNUR, 2019, p. 09). 
Sendo assim, as trabalhadoras refugiadas que, devido à condição de refúgio e ao gênero, são contratadas, principalmente, para trabalhos sem vínculos empregatícios, nos quais os salários são baixos e as jornadas de trabalho extensas, continuarão sem mecanismos protetivos capazes de coibir as violações as quais estão submetidas no mercado de trabalho brasileiro.

Contudo, com a modificação deste cenário, observa-se que o acesso ao trabalho e à remuneração dignos, possibilita a integração efetiva destas mulheres no Brasil e, desta forma, o acesso a outros direitos sociais, como saúde, educação, moradia, se torna mais tangível.

Além disso, o acesso ao trabalho digno faz com que as vulnerabilidades que marcaram as trajetórias das refugiadas até chegarem ao Brasil sejam amenizadas ou superadas, tendo vista que, com a melhora de suas condições econômicas, o acesso a demais política pública será mais facilmente alcançado e, assim, ocorrerá a efetiva integração local deste grupo.

Por isto, ao analisar as perspectivas das mulheres refugiadas trabalhadoras no Brasil, deve-se considerar que estas são oriundas de um contexto de violências, e, apesar das legislações brasileiras servirem de esteio para a defesa dos seus direitos sociais e trabalhistas, entendese necessário que o governo brasileiro realmente reconheça o protagonismo e dignidade destas mulheres por meio da efetivação de medidas que, de fato, minimizem a vulnerabilidade a qual estão expostas. Entretanto, o atual cenário laboral das refugiadas no Brasil mostra que, ao invés de caminhar na direção da proteção dos direitos humanos das mulheres em condição de refúgio, há a legitimação da manutenção do poder do capitalismo neoliberal sobre a dignidade destas mulheres.

Ante esta conjuntura, pontua Marinucci:

O trabalho, em muitos casos, deixou de ser um valioso instrumento de incorporação nas sociedades de chegada para se tornar um vetor de discriminação 
e exclusão social. Um verdadeiro muro para além dos muros das fronteiras (MARINUCCI, 2017, p. 01).

Desta feita, resta evidenciado que considerar as refugiadas como agentes ativos do fenômeno da mobilidade humana, a fim de que se manifestem discursivamente no processo de elaboração de políticas públicas de acolhimento, que devem ser criadas com base nas suas demandas específicas, sobretudo naquelas que auxiliem a minimizar as desigualdades de gênero, e assegurar a estas mulheres o acesso ao trabalho digno, consistem em efetivos mecanismos de integração local e, consequentemente, de superação de suas vulnerabilidades relativas à condição de refúgio e de gênero.

\section{Referências}

ACNUR, Perfil Socioeconômico dos refugiados no Brasil. Disponível em: https://www.acnur.org/portugues/wpcontent/uploads/2019/05/Resumo-Executivo-Versa\%CC\%83oOnline.pdf. Acesso em: 17 fev. 2020.

ACNUR. Declaração de Cartagena, Cartagena, Colômbia: Colóquio sobre Proteção Internacional dos Refugiados na América Central, México e Panamá: Problemas Jurídicos e Humanitários, 1984. Disponível em: http:/ / www.acnur.org/fileadmin/scripts/doc.php?file=fileadmin/ Documentos/portugues/BD_Legal/Instrumentos_Internacionais/D eclaracao_de_Cartagena. Acesso em: 17 ago. 2020.

ASSIS, Gláucia de Oliveira. Nova lei de migrações no Brasil: avanços e desafios. In: BAENINGER, Rosana et al. Migrações Sul-Sul. Campinas: Núcleo de População "Elza Berquó" - Nepo Unicamp, 2018. Disponível

em: http://www.nepo.unicamp.br/publicacoes/livros/migracoes_sul_s ul/migracoes_sul_sul.pdf. Acesso em: 17 fev. 2020.

AYDOS, Mariana; BAENINGER, Rosana; DOMINGUEZ, Juliana Arantes. Condições de Vida da População Refugiada no Brasil: trajetórias migratórias e arranjos familiares. In: Congresso da Associação Latino Americana de População, Alap, III., 2008, Córdoba, Argentina. Anais [...] Campinas: Nepo/Unicamp, 2008. Disponível 
em: http://obs.org.br/refugiados/938-condic-o-es-de-vida-dapopulac-a-o-refugiada-no-brasil-trajetorias-migratorias-e-arranjosfamiliare. Acesso em: 17. fev. 2020.

BEAUVOIR, Simone de. O segundo sexo: fatos e mitos. 4. ed. São Paulo: Difusão Europeia do Livro, 1976.

BRASIL. Lei $n^{\circ} 9.474$ de 22 de julho de 1997. Define mecanismos para a implementação do Estatuto dos Refugiados de 1951, e determina outras providências. Diário Oficial da União, Poder Executivo, Brasília, DF, 23 jul. 1997. Disponível em: https:/ / www2.camara.leg.br/legin/fed/lei/1997/lei-9474-22-julho1997-365390-publicacaooriginal-1-pl.html. Acesso em: 13 fev. 2020.

BRASIL. Lei no 13.445 de 24 de maio de 2017. Institui a Lei de Migração. Diário Oficial da União, Poder Executivo, Brasília, DF, 24 maio 2017. Disponível em: http://www.planalto.gov.br/ccivil_03/_Ato20152018/2017/Lei/L13445.htm. Acesso em: 17 fev. 2020.

BRASIL. Ministério da Justiça. Secretaria de Assuntos Legislativos (SAL). Migrantes, apátridas e refugiados: subsídios para o aperfeiçoamento de acesso a serviços, direitos e políticas públicas no Brasil. Pensando o Direito, n. 57, Brasília: IPEA, 2015. Disponível em: http:/ / pensando.mj.gov.br/wp-

content/uploads/2015/12/PoD_57_Liliana_web3.pdf. Acesso em: 13 fev. 2020.

HALL, Stuart. Da diáspora: identidades e mediações culturais. Belo Horizonte: UFMG, 2003.

IOM. World Migration Report 2018. Geneva, Switzerland: International Organization for Migration 2018. Disponível em: https:/ /www.iom.int/wmr/world-migration-report-2018. Acesso em: 23 jan. 2020.

IOM. World Migration Report 2020. Geneva, Switzerland: International Organization for Migration 2020. Disponível em: https:/ / publications.iom.int/system/files/pdf/wmr_2020.pdf. Acesso em: 17 ago. 2020.

ITAMARATY. Refugiados e CONARE. Disponível em: http:// www.itamaraty.gov.br/pt-BR/politica-externa/paz-e- 
seguranca-internacionais/153-refugiados-e-o-conare. Acesso em: 05 fev. 2018.

JUBILUT, Liliana Lyra. O direito internacional dos refugiados e sua aplicação no orçamento jurídico brasileiro. São Paulo: Método, 2007. Disponível em:

http:// www.acnur.org/t3/fileadmin/Documentos/portugues/Pub licacoes/2013/O_Direito_Internacional_dos_Refugiados.pdf?view $=1$ . Acesso em: 08 fev. 2018.

LIMA, João Brígido Bezerra et al. Refúgio no Brasil: caracterização dos perfis sociodemográficos dos refugiados (1998-2014). Brasília: IPEA, 2017.

Disponível

em: http://www.ipea.gov.br/portal/index.php?option=com_content\&v iew $=$ article\&id=30866. Acesso em: 17 ago. 2020.

LUSSI, Carmem. Políticas públicas e desigualdades na migração e refúgio. Psicologia USP, São Paulo, v. 26, n. 2, p. 136-144, maio/ago. 2015. Disponível em: http://www.scielo.br/pdf/pusp/v26n2/01036564-pusp-26-02-00136.pdf. Acesso em: 17 ago. 2020.

MARINUCCI, Roberto. Migrações e trabalho: precarização, discriminação e resistência. REMHU, Ver. Interdiscip. Mobl. Hum., Brasília, v. 25, n. 49, 2017. Disponível em: https:/ / www.scielo.br/pdf/remhu/v25n49/1980-8585-REMHU-2549-007.pdf. Acesso em: 17 fev. 2020.

MILESI, Rosita; MARINUCCI, Roberto. Mulheres migrantes e refugiadas a serviço do desenvolvimento humano dos outros. Cadernos de Debates Refúgio, Migrações e Cidadania, Brasília, v. 10, n. 10, p. 55-69, 2015.

MORALES, Ofelia Woo. Aprofundamento. La Migración de las mujeres ¿Um proyecto individual o familiar? REMHU - Rev. Interdiscip. Mobil. Hum., Brasília, v. 15, n. 29, p. 23-45, 2015.

MOREIRA, Julia Bertino. Refugiados no Brasil: reflexões acerca do processo de integração local. REMHU - Interdiscip. Mobil. Hum. Brasília, v. 22, n. 43, p. 85-98, jul./dez. 2014.

MOROKVASIC, Mirjana. Birds of Passage are also Women. The International Migration Review, v. 18, n. 4, p. 886-907, 1984. 
ONU. Convenção Relativa ao Estatuto dos Refugiados. Genebra: Assembleia Geral das Nações Unidas, 1951. Disponível em: http://www.acnur.org/t3/fileadmin/Documentos/portugues/BDL /Convencao_relativa_ao_Estatuto_dos_Refugiados.pdf?view $=1$. Acesso em: 17 ago. 2020.

ONU. Uma em cada cinco refugiadas são vítimas de violência sexual no mundo. ONU Mulheres, 2017. Disponível em: http:/ / www.onumulheres.org.br/noticias/uma-em-cada-cincorefugiadas-sao-vitimas-de-violencia-sexual-no-mundo/. Acesso em: 17 fev. 2018.

ORGANIZAÇÃO INTERNACIONAL PARA AS MIGRAÇÕES (OIM). Direito Internacional da Migração. Glossário sobre migração, Genebra, Suíça: Organização Internacional para as Migrações, 2009. Disponível em: $\quad$ http://publications.iom.int/system/files/pdf/iml22.pdf. Acesso em: 17 ago. 2020.

SAFFIOTI, Heleith. A mulher na sociedade de classes: mito e realidade. Petrópolis: Vozes, 1976.

SCHWINN, Simone Andrea; COSTA, Marli Marlene Moraes da. A discriminação múltipla sobre as mulheres migrantes. In: MEJÍA, Margarita Rosa Gaviria. Migrações e direitos humanos: problemática socioambiental. Lajeado: Ed. da Univates, p. 197-207, 2018.

SCHWINN, Simone Andrea; COSTA, Marli Marlene Moraes da. Mulheres refugiadas e vulnerabilidade: a dimensão da violência de gênero em situações de refúgio e as estratégias do acnur no combate a essa violência. Signos, Lajeado, v. 37, n. 2, p. 216-234, 2016.

UNHCR; UNFPA; WRC. Initial Assessment Report: Protection Risks for Women and Girls in the European Refugee and Migrant Crisis. UNHCR The UN Refugee Agency, 2015. Disponível em: http:/ / www.unhcr.org/569f8f419html\#_ga=1.121411469.469997879. 1453981260. Acesso em: 17 ago. 2020.

VENTURA, Deisy de Freitas Lima. “Regulamento da Lei da Migração é uma catástrofe", diz especialista. Carta Capital, 2017. Disponível em: https:/ / www.cartacapital.com.br/politica/regulamento-da-lei-damigracao-e-uma-catastrofe-diz-especialista. Acesso em 17 ago. 2020. 